\title{
Contraceptive satisfaction among women with sickle cell anemia
}

\begin{abstract}
Objective: to test the hypothesis that there is a difference in the contraceptive satisfaction of women with sickle-cell anemia (SC) using long-acting reversible contraceptive methods (LARC) and depot medroxyprogesterone acetate (DMPA).

Methods: cross-sectional study performed at two reference centers for SC women in Bahia, Brazil during 2016. Women with SC were included in reproductive age, who had been using a LARC or DMPA for more than 3 months. Were excluded women post-tubal sterilization, with hearing impairment, or on use of medications that could interfere with the reliability of the data. A structured questionnaire was used to collect reproductive and sociodemografic variables. Contraceptive satisfaction was analyzed by grouping a Likert scale (1- satisfied and very satisfied, 2-indifferent, 3 - unsatisfied and very unsatisfied).
\end{abstract}

Results: A total of 66 patients were included, 22 in LARC group and 44 in DMPA group. LARC group used it for less time $(31.8 \%$ vs. $75 \%, p=0.002)$, reported more irregular bleeding ( $36.4 \%$ vs. $12.5 \%, \mathrm{p}=0.038)$, higher levels of general satisfaction (1 [1-2] vs. 2 $[2-2], \mathrm{p}=0.012)$ and less dysmenorrhea $(45.5 \%$ vs. $84.4 \%, \mathrm{p}=0.002)$ when compared to DMPA group.

Conclusion: In this population, users of LARC were more satisfied than users of DMPA.

Keywords: sickle cell anemia, women's health, contraception;, patient satisfaction, contraceptive methods
Volume 6 Issue I - 2020

\author{
Flavia Pimentel Miranda,' Milena Bastos \\ Brito $^{2}$ \\ 'Department of health Sciences, Salvador University (UNIFACS), \\ Brazil \\ ${ }^{2}$ Bahian School of Medicine and Public Health, Brazil
}

Correspondence: Milena Bastos Brito, Adjunct Professor of the Bahian School of Medicine and Public Health, Salvador, Bahia, D. João VI, 275 - Brotas, Salvador - BA, Brazil. Zip Code: 40285$00 \mathrm{I}, \mathrm{Tel}+55-7|-3276-8265 ; \mathrm{Fax}+55-7|-3276-8202$,

Email milenabrito@bahiana.edu.br

Received: Augsut 18, 2019 | Published: January 10, 2020

\section{Introduction}

In world, hemoglobinopathies are present in $5 \%$ of the population. Each year about 300,000 children are born with some of them, and 200,000 cases are distributed only on the African continent. ${ }^{1}$ In Brazil (BR) about 7.2 million individuals have the sickle cell trait, a prevalence of 2 to $8 \%$ of the population with the asymptomatic heterozygous condition. ${ }^{2}$ Sickle cell anemia (SC) is one of the most prevalent hemoglobinopathies among sickle cell disease. ${ }^{3}$ Its presence reduces blood circulation velocity, which can lead to vaseocclusion, ischemia, chronic and/or acute pain subsequent to tissue and functional damage, in addition to chronic early hemolysis. ${ }^{1}$ The unplanned pregnancy rate in this population reaches $53 \%{ }^{4}$ Gestation in women with SC is associated with high maternal-fetal morbidity, ${ }^{3}$ high rates of abortion, stillbirths, preterm birth, restricted intrauterine growth and cesarean sections. ${ }^{5,6}$ As a strategy to reduce associated maternal-fetal damage, reproductive planning actions emerge. ${ }^{7}$

Among these actions, improve the use of long-acting reversible contraceptives methods (LARCs), represented, in Brazil, by copper intrauterine device (Cu-IUD), levonorgestrel-releasing intrauterine system (LNG-IUS) and etonogestrel-releasing contraceptive implant, could be an important improvement healthcare quality for women with SC. LARCs are more effective (associated with 20 times less chance of failure than short acting-reversible contraceptives), have higher continuation and satisfaction rates than short-acting reversible contraceptive methods (pills, injectables, vaginal ring and transdermal). ${ }^{8}$ However, less than $1 \%$ of Brazilian women use LARCs, contributing to high rates of unplanned pregnancy in the country (55\%). ${ }^{9}$ Although LARC options, only the Cu-IUD is available through the Unified Health System (SUS) for free in Brazil.
LARC use in the United States has shown a reduction in unplanned pregnancies and health costs. ${ }^{8}$ Among the short-acting reversible contraceptive methods, depot medroxyprogesterone acetate (DMPA) is a widely used method in Brazil, since it is available for free through SUS, quarterly use, low failure rate, besides the improvement of hematological and clinical parameters in patients with SC. ${ }^{10,11}$ Public sexual and reproductive health policies should guarantee access and continuation for the use of contraceptive methods, thus guaranteeing a ideal family planning, especially among women with high gestational morbidity and mortality, such as those with SC. To achieve the objective of contraceptive continuation, contraceptive satisfaction is of fundamental importance. In view of the high unplanned pregnancy rates reported in this group of patients, ${ }^{4}$ the importance of reproductive planning and the lack of research that assesses the satisfaction of these women in relation to the contraceptive method in use, the present study intends to test the hypothesis that there is a difference in the contraceptive satisfaction of women with SC using LARC and DMPA.

\section{Materials and methods}

This is a cross-sectional study of women sexually active, at reproductive age (18-49 years) and with SC (hemoglobin SS) who had been using DMPA or LARC for more than three months, a period in which there is a better adaptation to the method. ${ }^{12}$ Exclusion criteria were: women after tubal ligation, with hearing impairment, or using medications, such as benzodiazepines, that could interfere in the reliability of the data collected. The study was conducted in two reference centers for people with SC in Bahia, Brazil, from February to December 2016. Although there is a questionnaire that evaluates the satisfaction of contraceptive methods ${ }^{13}$ up to the time of data collection in this study, there was no instrument validated in Brazil 
that evaluated the contraceptive satisfaction of women with sickle cell anemia, being the first study to evaluate this group. We believe that the satisfaction of the method in these women cannot be equated with women of the general population, due to peculiarities that involve the context of the disease. Thus, an instrument with a sociodemographic and reproductive profile characterization approach and satisfaction of the contraceptive use in this group was constructed, which was based on existing and validated questionnaires, adapted to the context of the disease. A Delphi panel, ${ }^{14}$ with five national experts in the area of contraception, was conducted in two rounds.

Likert scale was used to evaluate satisfaction with contraceptive method. Answers were given as: 1-Very satisfied, 2-Satisfied, 3-Indifferent, 4-Unsatisfied, 5-Very Unsatisfied. To compare satisfaction with other variables (bleeding pattern, pain crisis and hydroxyurea use), items were grouped as 1-Very satisfied / Satisfied, 2-Indifferent, and 3-Unsatisfied/Very dissatisfied). This study was approved by institutional review board of Salvador University $\left(\mathrm{n}^{\circ}\right.$. 50675115.5.0000.5033). All patients signed the informed consent form. The sample calculation was based on Peipert et al., ${ }^{8}$ which assessed contraceptive satisfaction. Thus, we assumed a proportion of $90 \%$ satisfaction of women in LARC use and a $50 \%$ proportion of women's satisfaction with non-LARC use in relation to the method in use, a power of $80 \%$ and a confidence interval of $95 \%$, thus requiring 40 patients, 20 in each group.

Data were analyzed using the Statistical Package for Social Sciences (SPSS) version 14 for Windows. The evaluation of normality was made for descriptive statistics by Shapiro-Wilk test. To compare numerical variables with normal distribution between groups, the independent $\mathrm{t}$ test was used; and with a non-normal distribution the Mann-Whitney test. In the analytical statistic, the Mann-Whitney test was used to evaluate the association between satisfaction among the groups; and to evaluate the association between the categorical variables and the groups we used the chi-square test, $\mathrm{p}<0.05$ was considered significant.

\section{Results}

Ninety women were invited, 72 accepted and were included but five were excluded due to tubal sterilization, resulting in 66 participants: 44 in DMPA group and 22 in LARC group, 18 used etonogestrel-releasing contraceptive implant and 4 LNG-IUS. Most women were between the ages of 29 and 39, declared color as black or brown, and are single. There was no socio-demographic variables difference between groups (Table 1).

Regarding the reproductive profile, women referred to the occurrence of pregnancies (2 [1-2,5], childbirth (1 [1-2]), abortions (1 [1-2]), fetal and neonatal deaths $(75 \%)$, preterm births $(40 \%)$ and most cesarean deliveries (50\%) (Table 2). And there was also no difference between groups, except for contraceptive time of use, which was major among DMPA users than LARC users, for more than 12 months ( $75 \%$ vs. $31.8 \%, p=0.002$ ). When we evaluated the occurrence of adverse effects between groups, dysmenorrhea was more frequently reported among women who used DMPA than LARC (84.4\% vs. $45.5 \%, p=0.002$ ) (Table 3).

Women who reported little or no bleeding were more satisfied $(90.5 \%$ vs. $66.7 \%, p=0.004)$. However, when assessing the contraceptive satisfaction variable alone, women using LARC were more satisfied than DMPA users (1 [1-2] vs. 2 [2-2], p=0.012) (Figure
1). There were no difference regarding satisfaction and pain crisis or hydroxyurea use.

Table I Demographic and clinical Profile of women with sickle cell anemia

\begin{tabular}{llll}
\hline Variables & LARC & DMPA & $p$ \\
\hline \multirow{2}{*}{ Age ( $\pm S D)$} & $(n=22)(\%)$ & $(n=32)(\%)$ & \\
\cline { 2 - 3 } & $33.5 \pm 7.4$ & $30.2 \pm 8.6$ & $0.148 \mathrm{a}$ \\
\hline
\end{tabular}

Skin color

Black

$7(31.8)$

$18(56.3)$

Brown

$15(68.2)$

$14(43.8)$

0.077

Marital status

\begin{tabular}{|c|c|c|c|}
\hline Married & $8(36.4)$ & $10(3 \mid .3)$ & 0.695 \\
\hline Single & $14(63.6)$ & $22(68.2)$ & \\
\hline \multicolumn{4}{|l|}{ Religion } \\
\hline Catholic & $9(40.0)$ & $12(37.5)$ & \\
\hline Evangelical & II (55.0) & $1650.0)$ & 0.671 \\
\hline Has no religion & I (5.0) & $4(12.5)$ & \\
\hline \multicolumn{4}{|l|}{ Type for property } \\
\hline Own house & $17(77.3)$ & $21(65.6)$ & 0.357 \\
\hline Rented & $5(22.7)$ & II (34.4) & \\
\hline \multicolumn{4}{|l|}{ Family income } \\
\hline$\leq 1$ minimum wage* & $10(45.5)$ & $20(62.5)$ & 0.215 \\
\hline$>1$ minimum wage $*$ & $12(54.5)$ & $12(37.5)$ & \\
\hline \multicolumn{4}{|l|}{ Time of schooling } \\
\hline$\leq 10$ years & $3(18.8)$ & $2(12.5)$ & 0.626 \\
\hline$\geq 10$ years & $13(8 \mid .2)$ & $14(87.5)$ & \\
\hline \multicolumn{4}{|l|}{ Pain crisis } \\
\hline No & $7(31.8)$ & $9(28.1)$ & 0.77 \\
\hline Yes & $15(68.2)$ & 23 (7I.9) & \\
\hline Age of diagnosis $M(I Q)$ & $4(0-10.5)$ & $\begin{array}{l}6.0(0.3- \\
16.8)\end{array}$ & $0.393 b$ \\
\hline
\end{tabular}

$A$, independent $t$ test; $b$, mann-whitney test; $m$, mean; $S D$, standard deviation; $M$, median; IQ, interquartile range

Everyone else was held the Chi-square test.*minimum wage in the year 2016: U\$ 244.00 
Table 2 Reproductive profile of women with sickle cell anemia

\begin{tabular}{|c|c|c|c|}
\hline Variables & LARC & DMPA & $\mathbf{p}$ \\
\hline & $(n=16)$ a $(\%)$ & $(n=20) b(\%)$ & \\
\hline Pregnancy & $2(I-2.75)$ & $2(I-2.75)$ & $0.708 c$ \\
\hline Childbirth & I (I-2) & I (I-2) & $0.874 c$ \\
\hline Abortion & I (I-2) & I.5 (I-2) & $0.660 c$ \\
\hline \multicolumn{4}{|c|}{ Complications in pregnancy } \\
\hline Fetal/Neonatal death & $5(33.3)$ & $4(25)$ & 0.609 \\
\hline Prematurity & $5(4 I .7)$ & $10(62.5)$ & 0.274 \\
\hline \multicolumn{4}{|l|}{ Delivery } \\
\hline Vaginal & $4(25.0)$ & $8(40)$ & \\
\hline Cesarean & $9(56.3)$ & $10(50)$ & 0.506 \\
\hline Forceps & I (6.2) & I (5) & \\
\hline
\end{tabular}

a, 06 women who used LARC were nulliparous; b, I 8 women who used LARC were nulliparous; c, test mann-whitney, For all other Chi-square

Table 3 Contraceptive adverse effects reported

\begin{tabular}{|c|c|c|c|}
\hline Adverse effects & LARC & DMPA & $\mathbf{p}^{*}$ \\
\hline & $(n=22)(\%)$ & $(n=32)(\%)$ & \\
\hline \multicolumn{4}{|c|}{ Nausea and vomiting } \\
\hline Yes & $10(45.5)$ & $13(40.6)$ & 0.724 \\
\hline \multicolumn{4}{|l|}{ Breast tenderness } \\
\hline Yes & $9(40.9)$ & $17(53.1)$ & 0.377 \\
\hline \multicolumn{4}{|l|}{ Pain } \\
\hline Yes & I $3(59.1)$ & $22(68.8)$ & 0.465 \\
\hline \multicolumn{4}{|l|}{ Dysmenorrhoea } \\
\hline Yes & $10(45.5)$ & $27(84.4)$ & 0.002 \\
\hline \multicolumn{4}{|l|}{ Irritability } \\
\hline Yes & $15(68.2)$ & $25(78.1)$ & 0.413 \\
\hline \multicolumn{4}{|l|}{ Acne } \\
\hline Yes & $4(18.2)$ & $9(28.1)$ & 0.401 \\
\hline
\end{tabular}

*Chi-square test

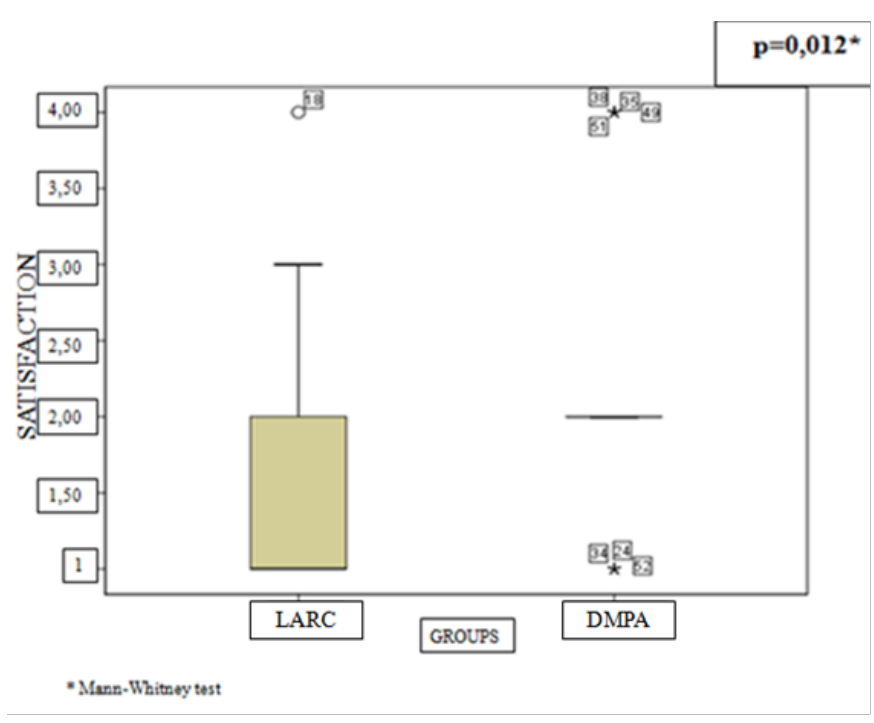

Figure I Boxplot of satisfaction overall contraceptive use in women with sickle cell.

\section{Discussion}

In the present study, it was observed that women with $\mathrm{SC}$ using LARC reported higher levels of contraceptive satisfaction compared to those using DMPA. However, they used the method for a shorter period of time, reported a higher occurrence of bleeding, and less dysmenorrhea. No previous studies were found addressing this issue among women with SC, being this the first study to evaluate the contraceptive satisfaction in this group. The global rates of contraceptive satisfaction could be related with the absence of dysmenorrhea reported by LARC group. This result is similar to the available literature, which evidences the complete resolution of dysmenorrhea, ${ }^{15}$ and an increase in quality of $l i f \mathrm{e}^{10}$ associated with the use of hormonal LARCs, which represented the entire sample of the present study.

Pain in the context of SC is a relevant aspect and present in the daily life of these women, so any contraceptive method that reduces its frequency or intensity could influence the contraceptive satisfaction evaluation. Dysmenorrhoea has repercussions on the development of daily activities and women quality of life, representing a public health problem, causing impairment due to absenteeism in the professional and school life. ${ }^{16}$ When dysmenorrhea is present, the woman may discontinue the method or think another contraceptive option. Patients using DMPA reported more reduction in vaginal bleeding or amenorrhea than LARC group. Although patients who were more satisfied also referred the same bleeding pattern, contradicting the result of the evaluation of the contraceptive satisfaction, when evaluated in isolation. However, this finding is possibly related to the time of use of the method, which was higher in the DMPA group, since studies show higher rates of amenorrhea after 12 months with DMPA use. ${ }^{16}$

The contraceptive satisfaction reported by LARC group may also have been influenced by counseling about pre and post-insertion of the methods. Counseling about what to expect from bleeding disorders is a fundamental strategy and results in low discontinuation rates and higher levels of satisfaction. ${ }^{17}$ The CHOICE project showed 
that $75 \%$ of the women chose to use LARCs. ${ }^{18}$ It also showed that continuation and satisfaction rates were higher among LARCs users when compared to short-term contraceptive methods $(86.2$ versus $54.7 \%$ ), a result similar to the present study. ${ }^{19}$ Among LARCs, the etonogestrel-releasing contraceptive implant had the highest frequency, probably due to a temporary availability, at no cost, through the City Hall of Salvador. Thus, these patients have frequent followup and consequent referencing by the health professionals, they had access to the method, aspect that possibly also influenced the overall contraceptive satisfaction.

In the context of the disease, methods with progestogenonly are related to the absence of alterations in the risk of venous or arterial thrombosis, improvement of pain and haematological parameters,$^{20}$ aspects that possibly represent the proportion of DMPA users in this study, since that this is the only effective progestogenonly contraceptive method available for free in Brazil. The social vulnerability that these women are inserted can also be represented by the low family income referred to, as is known in other studies. ${ }^{21}$ This fact was confirmed by the patients' reports about the type of work they do, and residence in the periphery of the city. Often the only source of income is the benefit of sickness aid, provided by the Brazil Ministry of Social Security, which is divided up with family expenses.

Some aspects create limitations for this study. The study population represented a convenience sample, obtained in two reference centers, which tends to congregate people more aware of their disease process, and more resilient, which provides a shared contraceptive choice with professionals. Another issue concerns the design of the study. In the cross-sectional study, it is not possible to analyze causality. Thus, only prospective cohorts can evaluate the factors that influence contraceptive satisfaction. It is also known that because it is a structured interview, even with the training of the interviewers, the participant can provide a false answer, determined for conscious reasons or not, besides the inability to respond adequately, due to the lack of vocabulary.

\section{Conclusion}

Women with sickle cell anemia using LARC report greater contraceptive satisfaction than women users of DMPA. Public policies should be broadened with the objective of ensuring direct access to women of contraceptive free choice, through the inclusion of more modern contraceptive methods, effective and with higher rates of satisfaction. We will then have an effective and equal reproductive planning for the entire Brazilian population, especially for women with a high risk of morbidity and mortality during the gestational period, such as those with SC.

\section{Acknowledgments}

None.

\section{Conflicts of interest}

No conflicts to declare.

\section{Funding}

None.

\section{References}

1. World Health Organization. Sickle-cell disease and other haemoglobin disorders. 2011.
2. Fernandes APPC, Januário JN, Cangussu CB, et al. Mortality of children with sickle cell disease: a population-based study. J Pediatr (Rio J). 2010;86(4):279-284.

3. Zanette AMD. Pregnancy and contraception in sickle cell disease. Rev Bras Hematol Hemoter. 2007;29(3):309-312.

4. Eissa AA, Tuck SM, Rantell K, et al. Trends in family planning and counseling for women with sickle cell disease in the UK over two decades. J Fam Plann Reprod Health Care. 2015;41:96-101.

5. Santos SN, Surita FGC, Pereira BG. Maternal and perinatal outcomes in patients with sickle cell anemia. Rev Ciênc Med. 2005;14(5):415-419.

6. Nomura RMY, Igai AMK, Tosta $\mathrm{K}$, et al. Maternal and perinatal outcomes in gestations complicated by sickle cell disease. Rev Bras Ginecol Obstet. 2010;32(8):405-411.

7. Andemariam B, Browning SL. Current management of sickle cell disease in pregnancy. Clin Lab Med. 2013;33(2):293-310.

8. Peipert JS, Zhao Q, Allsworth JE, et al. Continuation and satisfaction of reversible contraception. Obstet Gynecol. 2011;117 (5):1105-1113.

9. Bahamondes L, Moazzam A, Monteiro I, et al. salts in the setting of the Zika virus epidemic. Hum Reprod. 2017;32(1):88-93.

10. Cristobal I, Lete LI, E Widoow, et al. One year quality of life measured with SEC-QoL in levonorgestrel $52 \mathrm{mg}$ IUS users. Contraception. 2016;93(4):367-371.

11. Abood M, Castillo Z, Guerrero F, et al. Effect of Depo-Provera or Microgynon on the painful crises of sickle cell anemia patients. Contraception. 1997;56(5):313-316.

12. Zigler RE, Mcnicholas CP. Unscheduled vaginal bleeding with progestin only contraceptive use. American Journal of Obstetrics and Gynecology. 2017;216(5):443-450.

13. Colwell HH, Mathias SD, Cimms TA, The ORTHO BC-SAT - The satisfaction questionnaire for women using hormonal contraceptives. What Life Res. 2006;15(10):1621-1631.

14. Wright JTC, Giovinazzo RA. 2000. Delphi - A tool to support prospective planning. Cad of Researches in adm. 12 (1): 54-65.

15. Mansour D, Korver T, Marintcheva-Petrova M, et al. The effects of Implanon on menstrual bleeding patterns. Eur $J$ Contracept Reprod Health Care. 2008;13(1):13-28.

16. Acqua RD, Bendlin T. Dysmenorrhea. Femina. 2015;43(6):274-276.

17. Hubacher D, Lopez L, Steiner MJ, et al. Menstrual pattern changes from levonorgestrel subdermal implants and DMPA: systematic review and evidence-based comparisons. Contraception. 2009;80(2):113-118.

18. Modesto W, Bahamondes MV, Bahamondes L. A randomized clinical trial of the effect of intensive versus non-intensive counseling on discontinuation rates due to bleeding disorders of three long-acting reversible contraceptives. Hum Reprod. 2014;29(7):1393-1399.

19. Klein JD, American Academy of Pediatrics Committee on Adolescence. Adolescent pregnancy: current trends and issues. Pediatrics. 2005;116(1):281-286.

20. Sedgh G, Finer LB, Bankole A, et al. Adolescent pregnancy, birth, and abortion rates across countries: levels and recent trends. J Adolesc Health. 2015;56(2): 223-230.

21. Austin H, Lally C, Benson JM, et al. Hormonal contraception, sickle cell trait, and risk for venous thromboembolism among African American women. Am J Obstet Gynecol. 2009;200(6):620. 